\title{
Matrix converters for sensorless control of PMSMs and other auxiliaries on deep-sea ROVs
}

\author{
P. Snary, B. Bhangu, C.M. Bingham, D.A. Stone and N. Schofield
}

\begin{abstract}
The use of matrix converter technologies for the control of actuators and other auxiliaries onboard work-class, deep-sea, remotely operated vehicles (ROVs) is reported. Key requirements for such systems are the ability to sustain operation at high ambient pressures, up to $300 \mathrm{bar}$, commensurate with operation of ROVs at depths of $3000 \mathrm{~m}$, and to minimise the number of external connections and cabling mass to improve reliability and reduce drag. Emphasis is given to $3 \times 2$ matrix converters for $3 \phi-1 \phi$ AC voltage/frequency for conversion control of system auxiliaries, with experimental results showing circuit functionality during pressure cycling consistent with typical operational duties, and the use of $3 \times 3$ matrix converters for control of actuators driven by brushless permanent magnet synchronous machines (PMSMs). A principal feature of the paper is the development of model-based sensorless control methodologies for driving PMSMs using matrix converters. In particular, it is shown that observer-based stateestimation techniques normally employed for sensorless control of PMSMs using voltage source inverters, can be readily exported to matrix converter counterparts with minimal additional computational overhead. Experimental results from a $0.7 \mathrm{~kW}$ PMSM driven by a matrix converter, suitable for a subsea actuator pump, are included to demonstrate the ability of the sensorless techniques to provide reliable estimates of machine rotor position under transient load conditions, and the subsequent exploitation for matrix converter/motor combinations is discussed.
\end{abstract}

\section{List of symbols}

\section{$B$}

$d_{x}, d_{y}, d_{z}$

$i_{d}$

$\hat{i}_{d}$

$\hat{I}_{o}$

$i_{q}$

$\hat{i}_{q}$

J

K

$K_{t}$

$L_{s}$

$p$
$R_{s}$

$\hat{T}_{L}$

$T_{s}$
$T_{x}, T$

$u$

$u_{d}$

$u_{q}$

$V_{a}(t), V_{b}(t), V_{c}(t)$

$V_{A}(t), V_{B}(t), V_{C}(t)$ motor viscous friction $\mathrm{Nm} \mathrm{s} / \mathrm{rad}$ duty components of switching period

$d$-axis motor current $\mathrm{A}$

estimate $d$-axis current $\mathrm{A}$

peak output current A $q$-axis motor current $\mathrm{A}$

estimate $q$-axis current $\mathrm{A}$

rotor inertia $\mathrm{Kg} / \mathrm{m}^{2}$

observer gain

back emf constant $\mathrm{V} / \mathrm{rad} / \mathrm{s}$

torque constant $\mathrm{Nm} / \mathrm{A}$

synchronous inductance $\mathrm{H}$

pole pairs

machine phase resistance $\Omega$

estimate load torque $\mathrm{Nm}$

switching time period $\mathrm{s}$

duty switching period s

observer input

auxiliary $d$-axis input $\mathrm{V}$

auxiliary $q$-axis input $\mathrm{V}$

machine $3 \phi$ supply voltage $\mathrm{V}$

$3 \phi$ supply input voltage to converter $\mathrm{V}$

$v_{d}$
$v_{d}^{\prime}$
$V_{d c}$
$V_{\text {in }}$
$V_{i n}$
$V_{\max }$
$V_{\min }$
$V_{o}$
$v_{q}$
$\hat{v}_{q}^{\prime}$
$V_{x}, V_{y}$
$V_{1}, V_{2}, V_{3}, V_{4}, V_{5}, V_{6}$
$y$
$\theta$
$\hat{\theta}$
$\theta_{0}$
$\theta_{s}$
$\omega$
$\hat{\omega}$

$d$-axis motor voltage $\mathrm{V}$ calculated $d$-axis terminal voltage $\mathrm{V}$ artificial DC-link voltage $\mathrm{V}$ RMS line input voltage $\mathrm{V}$ peak line input voltage $\mathrm{V}$ maximum input phase voltage $\mathrm{V}$ minimum input phase voltage $\mathrm{V}$ output space vector $\mathrm{V}$ $q$-axis motor voltage $\mathrm{V}$ calculated $q$-axis terminal voltage $\mathrm{V}$ sector switch-state vectors $\mathrm{V}$ switching state vectors $\mathrm{V}$ observer output output reference angle rad estimate rotor position rad electrical rotor position rad output vector sector angle rad rotor angular velocity $\mathrm{rad} / \mathrm{s}$ estimate rotor angular velocity $\mathrm{rad} / \mathrm{s}$

\section{Introduction}

Manufacturers of work-class deep-sea ROVs (see Fig. 1) are increasingly looking towards the replacement of traditional hydraulic based drive systems and other auxiliary equipment such as robot arms, cable-laying and burial equipment, by electric-based technologies [1,2]. Although electromagnetic machines have lower power density that 


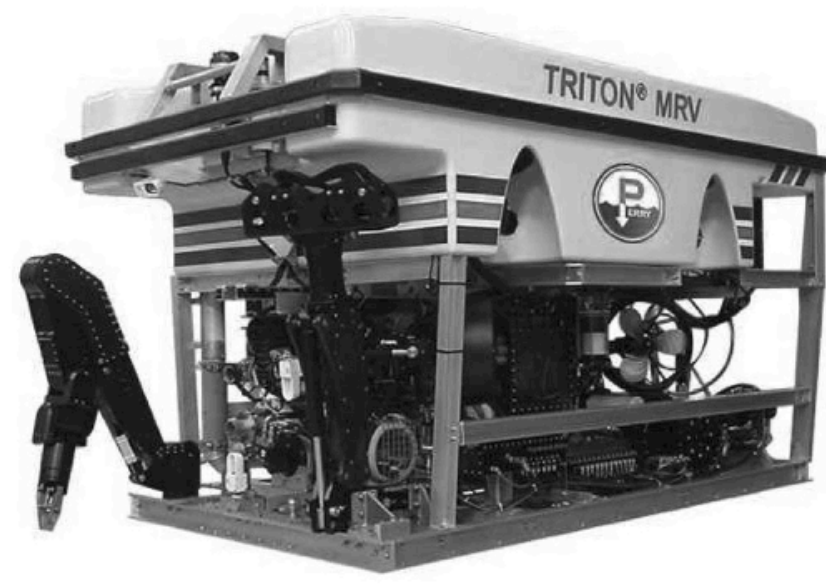

Fig. 1 Deep-sea $(3000 \mathrm{~m})$ remotely operated vehicle.

Photograph reproduced by permission of Perry Slingsby Systems Ltd., York, UK

their hydraulic counterparts, electrically based power units have the potential to offer significant system advantages in terms of higher reliability, reduced overall system mass, improved control dynamics and better energy efficiency $[1,2]$; the latter translating to a reduction in mass and drag from the umbilical cable connection for power transmission from a surface ship.

During deep-sea operation of the ROV, buoyancy constraints and cooling issues make it highly desirable to operate power electronic drive systems in an oil-filled environment subject to the high ambient pressure (up to 400 bar), as opposed to being housed in a thick-walled metallic pressure vessel subject to nominal atmospheric pressure (1 bar). However, capacitors (particularly electrolytic types) and some industrial-grade semiconductor devices are known to be extremely sensitive to pressure due to their construction, and can implode under pressures corresponding to $3000 \mathrm{~m}$ sea depth ( $\approx 300$ bar) [3]. As drive systems must withstand $\approx 300$ bar ambient, the components should ideally be able to withstand $\times 1.33$ this pressure ( $\approx 400$ bar) to provide an operating safety margin on the system components.

Consultation with electronic component manufacturers indicate that although it may be possible to package devices appropriately, and maintain rated performance, the relatively low production quantities required for this type of application will have a significant impact on unit costs. Moreover, for electric actuation and servosystems, such as those used on robot arms and for control of other auxiliaries, for instance, the traditional recourse to rectifier/voltage source inverters (VSIs) and AC-DC converters, is not considered to be the most practical solution, with matrix converter technologies now providing an attractive alternative. Although the adoption of matrix converters increases the number of active power devices and significantly increases control complexity, the higher reliability and reduced volume envelope resulting from the elimination of the relatively large electrolytic DC-link capacitor, is considered, on balance, to more than compensate. Moreover, by reducing the number of external wiring/connections [4] between the motor and inverter by employing sensorless commutation of permanent magnet synchronous machines (PMSMs), which traditionally require the use of encoder, resolver or Hall-effect signal feedback of rotor position, reliability can be further improved. In particular, it is shown that by employing only measured motor terminal quantities and observer-based rotor position estimation schemes, no external sensor signal connections (between motor and inverter) are necessary, since the required current/voltage transducers (which operate satisfactorily in high-pressure oil-filled environments, see Section 2) can be sited at the power converter within the high-pressure chamber. Eliminating the shaft mounted position sensors also reduces vibration-damage susceptibility with a corresponding reduction in maintenance requirement. In addition, it is expected that by using such schemes on a typical all-electric work-class ROV, possessing more than six electric thruster actuators and more than six (min) auxiliary servomotors, will ultimately result in a significant saving on connections/cable-mass. Furthermore, removing the necessity for an integrated rotor position sensor also simplifies the motor construction, since the special scaling requirements attributed to supporting correct operation of the sensor/electronics in the motor housing, in a harsh saline environment, are eliminated.

We consider typical commercially available power electronic and signal-conditioning devices appropriate for converter/drive systems that will maintain nominal operation in high-pressure environments. Application of such components to build a $3 \times 2$ matrix converter for the provision of a $3 \phi / 60 \mathrm{~Hz}$ to $1 \phi /$ variable-voltage/variablefrequency (or DC) supply, for powering auxiliary equipment, is subsequently considered. A detailed account of research activity to design and commission an observerbased sensorless drive system for a PMSM excited by a $3 \times 3$ matrix converter, to convert a $3 \phi / 60 \mathrm{~Hz}$ input to a $3 \phi /$ variable-voltage/variable-frequency output, suitable for powering variable-speed servoactuators, then follows. It is notable that although sensorless control of PMSMs has been extensively reported [5-10], their application is almost exclusively based on traditional six-switch voltage-source inverter systems (exceptions being reported in [11, 12]), with no material exploring observer-based techniques for use with matrix converters yet being available. More generically, therefore, it is also shown that by a convenient selection of matrix converter commutation strategy, the advantages of sensorless control of PMSMs can be directly exported to applications where matrix converters provide a preferred converter solution, as proposed here for deep-sea ROV systems (and, perhaps, more widely for some aerospace systems $[13,14])$. Furthermore, unlike the techniques reported in $[11,12]$ that employ stator flux estimators, it is shown that the proposed observer-based methodology additionally facilitates load-torque estimation that can be used to enhance the performance of outer-loop speed or position controllers.

\section{High-pressure electronic-circuit failure mechanisms}

Failure modes of power electronic devices subject to highpressure environments can be predicted by consideration of the components and their packaging. Three possible failure modes are:

(i) Total (irreversible) mechanical failure. Failure of devices due to the inability of the packages to withstand high ambient pressure, or pressure cycling, giving rise to total mechanical failure. This is a consequence of air voids or compressible materials within the packages reducing in volume under pressure, causing case implosion. This type of failure can often be induced by static pressure tests.

(ii) Changes in device characteristics: Deformation of the device casing causing component characteristics to deviate 
outside the permissible operating range, or ingress of insulating transformer oils into nonsealed devices leading to changes in device operating characteristics. Although the variation of some component values with pressure can be measured under static conditions e.g. the value of small electrolytic capacitors, the effects of pressure on active devices should be assessed under full duty-cycle operation.

(iii) Temporary (reversible) failure: The elastic properties of some component packaging may lead to the creation of temporary short-circuits within the devices, or the ingress of oil causing open-circuits, that may clear when the pressure is removed.

Predicted failure mechanisms are demonstrated in practice by subjecting commercial devices to target pressures within an oil-filled pressure chamber. Provisional static tests can determine device packages that can mechanically withstand target pressures. To identify less dramatic failures, devices are characterised electrically, both before and after the pressure cycling. Simple mechanical failure of a device can be readily identified by examining the package after pressure testing. Mechanical failure can often be dramatic, some examples of which are revealed in Fig. 2, which shows the failure of the quartz window on a EPROM device (a), the severe cracking experienced by the case of an intelligent power module (IPM) (b), and the compression of TO5 packages (c). It should be noted the devices labelled 'a' and ' $b$ ' are TO5 packages with $1 \mathrm{~mm}$ holes drilled into the casing to allow pressure equalisation. It is clear that such procedures enable the device case to mechanically withstand the test pressure better than devices 'c'-'e', which show damage due to the compression of the can lid to such a degree that the impression caused by the top of the device legs is visible. For completeness, results obtained from testing other typical components and packages are summarised in Table 1.

As might be expected, the results in Table 1 show that solid encapsulation of devices offers improved protection against pressure damage, with discrete power devices fairing significantly better than totally enclosed power modules. However, a number of devices that would be regarded as essential components of power converter systems, large electrolytic capacitors for instance, cannot withstand target pressures; a factor that has significant implications on the selection of appropriate power converter topologies for these applications.

\section{Selection of power converter topology}

From the results of component pressure tests it is apparent that alternatives to industry standard rectifier/VSIs (Fig. 3)
Table 1: Device test results after operation at $300 \mathrm{bar}$

\begin{tabular}{|c|c|c|}
\hline Devices & $\begin{array}{l}\text { mechanical } \\
\text { inspection }\end{array}$ & electrical test \\
\hline Miniature DC-DC converters & undamaged & operational \\
\hline Diode DO-41 & undamaged & operational \\
\hline Diode TO-220 & undamaged & operational \\
\hline Diode SOD-93 & undamaged & operational \\
\hline Diode DOP-31 & undamaged & operational \\
\hline Bridge rectifier & undamaged & operational \\
\hline IGBT TO-247 & undamaged & operational \\
\hline MOSFET TO-220 & undamaged & operational \\
\hline MOSFET HD-1 & undamaged & operational \\
\hline MOSFET TO-247 & undamaged & operational \\
\hline BJT TO-92 & undamaged & operational \\
\hline BJT E-line & undamaged & operational \\
\hline ВJT TO-5/TO-18 & concave & failed \\
\hline BJT TO-5/TO-18 (drilled) & OK, hole in top & failed \\
\hline IGBT based IPM module & cracked & failed \\
\hline EPROM windowed & imploded & failed \\
\hline Logic (nonwindowed) & undamaged & operational \\
\hline Variable resistors & undamaged & failed \\
\hline Current transducer & undamaged & operational \\
\hline Current transducer (drilled) & OK, hole in top & operational \\
\hline Resistors & undamaged & operational \\
\hline Miniature inductors & undamaged & operational \\
\hline ETD49 former: F44 core & undamaged & operational \\
\hline Ceramic capacitors & undamaged & operational \\
\hline Polyester capacitors & undamaged & operational \\
\hline Tantalum capacitors & undamaged & operational \\
\hline Polystyrene capacitors & undamaged & operational \\
\hline $\begin{array}{l}\text { Miniature aluminium } \\
\text { electrolytic }\end{array}$ & undamaged & $\begin{array}{l}\text { out of } \\
\text { specification }\end{array}$ \\
\hline DC-link electrolytic capacitors & concave & failed \\
\hline Optical devices & undamaged & operational \\
\hline
\end{tabular}

and traditional $\mathrm{AC} / \mathrm{DC}$ converters are desirable, since these topologies require large reactive energy storage components (electrolytic capacitors being particularly problematic). Matrix converter technologies [13-20] present a natural candidate, Fig. 4, since, unlike the conventional rectifier/ inverter counterparts viz. voltage- and current-source variants, converters based on a switch matrix do not
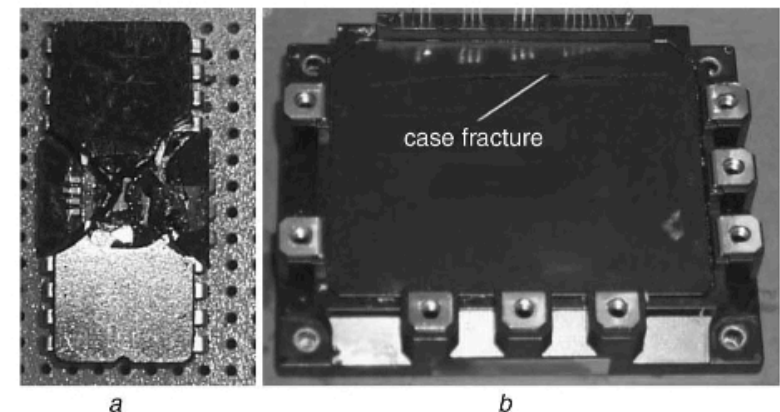

$b$

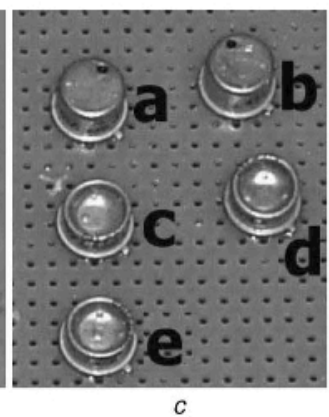

Fig. 2 Mechanical failure after 300 bar pressure tests $a$ windowed UVEPROM

$b$ IPM

$c$ TO5 cans 


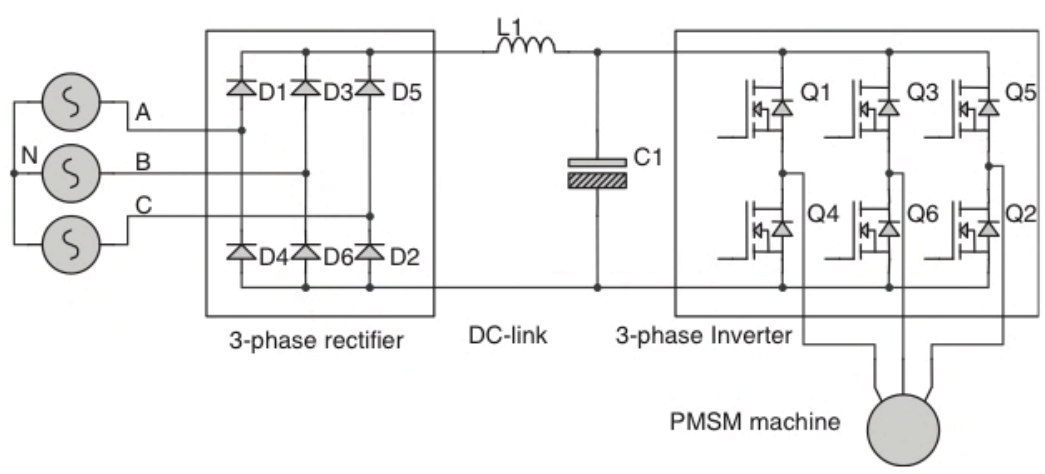

Fig. 3 Configuration of a typical rectifier/VSI

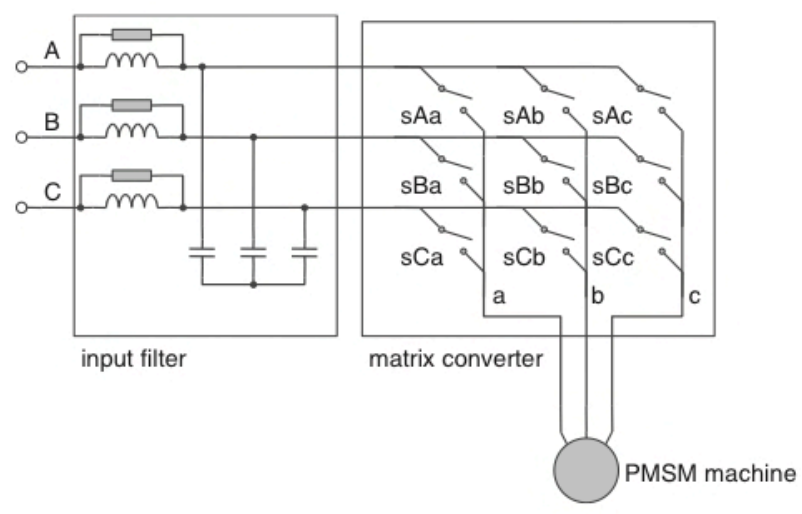

Fig. 4 Configuration of a typical matrix converter showing inline filter components

require a two-stage (rectifier/inverter) conversion process, with the consequential elimination of the intermediate reactive energy storage component. Moreover, since no significant capacitance is required, other than for small line filters to reduce switching harmonics, they also circumvent additional problems attributed to electrolytic capacitors with regard to physical size, ripple current rating, thermal cycling and reliability. Furthermore, reactive components that are required for the inline filters can utilise pressuretolerant capacitor technologies such as foil or metalised polypropylene.

It is widely recognised that a key disadvantage of matrix converters is the increased number of power switches (nine bidirectional) compared to traditional six-switch inverters, and the potential for increased switching losses incurred by virtue of the requirement for complex commutation switching strategies (particularly at low power), thereby requiring larger heatsinks or additional cooling mechanisms. However, for this application field the impact of greater switching losses can be abated to some degree by careful design and mounting of power devices onboard the ROV, since deep-sea operation can make use of the effective 'infinite' heat-sink provided by the external environment, as the oil-filled containment is in direct contact with the seawater. Although this feature also applies to power switches of VSI counterparts, the additional mass/volume envelope required for a matrix converter solution is largely limited to that required for mounting of the extra power devices, and is countered by the requirement for large DC-link capacitors in VSIs, a feature that does not necessarily carry over to other application fields that consider matrix converters as alternatives to VSIs (e.g. aerospace systems). Appropriate thermal management then focuses on the requirements for 'functionality testing' of the systems on the surface vessel prior to operation.

\section{1 $1 \times 1$ switching matrix}

The most basic form of matrix converter is the single-phase AC-AC 'transformer', consisting of two bidirectional switches configured in a half-bridge arrangement, (see Fig. $5 a$ ). Although simple in structure, this configuration allows a continuously variable step-down voltage ratio (but no frequency control) and is therefore suitable for simple power control applications such as variable intensity lighting. The bidirectional switch arrangement also forms a generic element for other standard matrix converter structures, for instance the $3 \times 2$ (Fig. $5 b$ ) and $3 \times 3$ (Fig. $5 c$ ) converters. To ensure sustained operation at high pressure, each bidirectional switch consists of two MOS-

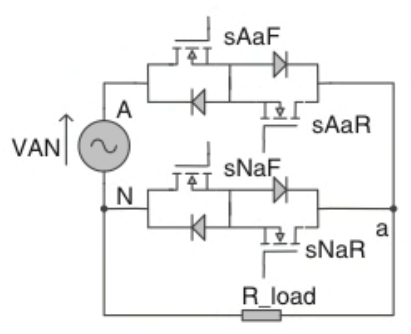

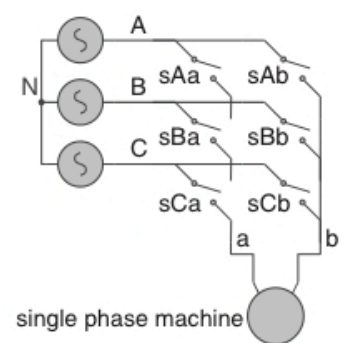

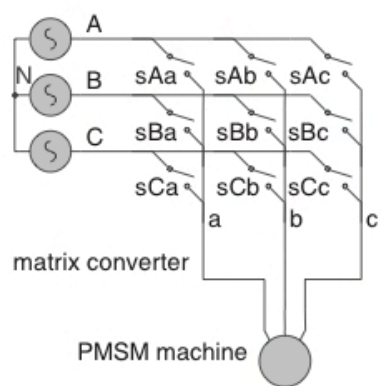

Fig. 5 Matrix converter topologies

$a 1 \phi-1 \phi$ illustrating bidirectional switch configuration

$b 3 \phi-1 \phi$ variable voltage/variable frequency

c $3 \phi-3 \phi$ variable voltage/variable frequency 
FETs internally connected in common source mode (see Fig. 5a) within a C4-10s1 SmartPak package that has been previously demonstrated to withstand high-pressure operation [3]. Although this switch configuration/packaging solution has been developed specifically for this application, investigations have revealed that most devices encapsulated in solid epoxy packages are able to operate reliably at elevated ambient pressures, thereby allowing the connection of more generic off-the-shelf devices to be employed to form the bidirectional switches if required. A multistep commutation technique [19] is adopted that prevents simultaneous conduction of the two switches while ensuring a freewheeling current path for the load. For completeness, the four-step voltage commutation sequence used in all variants of the matrix converters considered here, is illustrated in Fig. 6. Measured voltage and current waveforms from a prototype $1 \times 1$ converter during the final stage of pressure profile tests, Fig. 7a, are shown in Fig. 7b. The converter would typically be used to provide variable intensity task lighting onboard the ROV. Although the output frequency is fixed to that of the input, it is clear that with appropriate pulse width modulation (PWM) and commutation the output voltage can be varied, and by appropriate selection of packaging, operation at high pressures has been sustained.
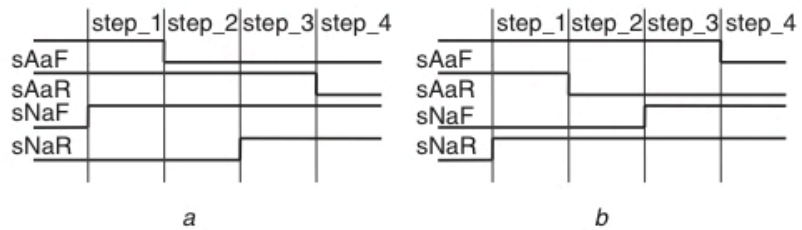

Fig. 6 Commutation sequence for $1 \times 1$ converter $a$ voltage commutation for case $V_{A N}$ positive

$b$ voltage commutation for case $V_{A N}$ negative

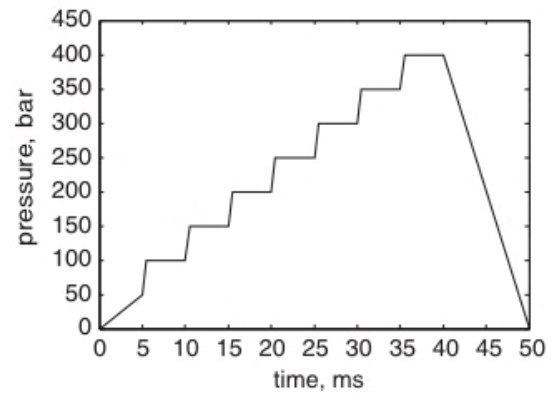

a

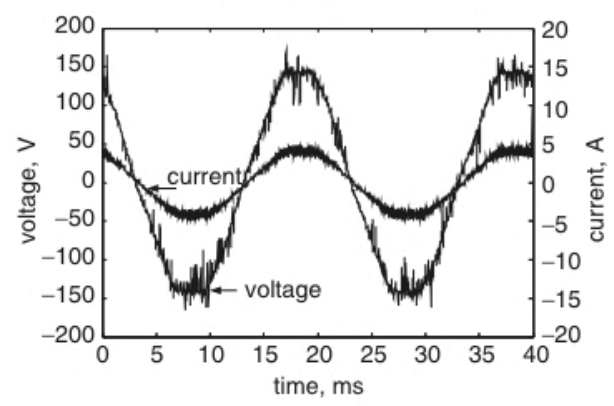

b

Fig. 7 Prototype $1 \times 1$ converter

$a$ test pressure profile

b Output voltages and currents, converter operating at $400 \mathrm{bar}$

\section{$3.23 \times 2$ Switching matrix}

For more advanced power conversion applications, an increased number of bidirectional switches are required, resulting in complex control structures. For instance, to obtain $3 \phi-1 \phi$ conversion with independent amplitude and frequency control, a converter employing six bidirectional switches is required. Termed a $3 \times 2$ matrix converter, this topology is suitable for onboard applications such as singlephase localised pump drives and DC supplies. The use of a $3 \times 2$ matrix converter for single-phase loads may be preferred when connecting to a limited capacity 'island' power system such as encountered onboard an ROV, as relatively large single-phase loads can lead to undesirable unbalanced operation.

Figure $8 a$ shows a prototype, $1 \mathrm{~kW}, 3 \times 2$ matrix converter (see Fig. $5 b$ ), the power devices being mounted on the underside of the printed circuit board (PCB).

Although three-phase sinusoidal input currents are not possible with this topology due to output current passing through zero twice per cycle, a simple 'rectifier input' control algorithm [20] with voltage commutation is used to control the converter. This also reduces the computational overhead compared to full input and output space vector PWM. Voltage commutation is used in preference to current commutation in this case to avoid the requirement for additional current measurement sensors.

The prototype converter has been demonstrated to operate over a range of output frequencies when subjected to typical operating pressures (as in Fig. 7a) as illustrated in Fig. 9. Of particular note for this type of application is the impact of parasitic capacitance from the power switches and the distributed capacitance attributed to the use of cables connecting the machine to the converter. Results obtained from converter tests under low supplyline voltage conditions, both with and without cables attached to the output, are shown, respectively, in Fig. $10 a$ and 10b. The switching event depicted is from the zero vector $\mathrm{A}(\mathrm{sAa}, \mathrm{sAb})$ to the power vector $\mathrm{B}(\mathrm{sBa}, \mathrm{sAb})$ (definition of the switches are as shown in Fig. $5 b$ ). The results clearly demonstrate that although the output cables are short, possibly a maximum of $10 \mathrm{~m}$, this screened type of cable has a small distributed capacitance that increases the amplitude of the current transition through devices $\mathrm{sBa}$ and $\mathrm{sAb}$, due to the transient voltage change across this capacitance and that of the bidirectional switch (Fig. 11). The amplitude of the current flowing through the phase not involved in the commutation action (phase $\mathrm{C}$ in this case), remains constant, independent of whether or not the output cables are present. Under ideal conditions, however, no current would flow in phase $\mathrm{C}$ since no commutation event in that phase takes place. It is also apparent that the additional capacitance of the cables leads to a frequency shift in the ringing cf. Figs. $10 a$ and $10 b$. Although these transients and 'ringing' may marginally affect the electromagnetic emissions from the system, they are unlikely to constitute a significant proportion of the overall system losses.

\section{$3.33 \times 3$ switching matrix}

Various sectors of the vehicle industry viz. automotive, aerospace and in this case, marine, are currently accelerating through a transitional phase of replacing hydraulic components of drive-trains and actuators with electric machines. Consequently, the power-to-weight advantages and thermal characteristics attributed to PMSMs are making them a preferred option for many electromechanical servosystems. The requirement for variable speed servocontrol of these machines necessarily requires independent control of the motor phases, thereby traditionally 

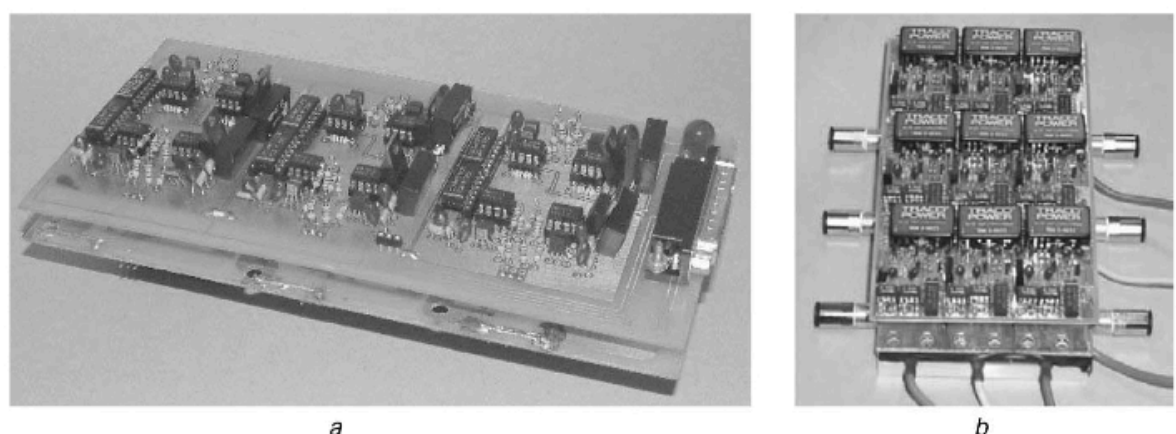

Fig. 8 Matrix converters

a $3 \times 2$ switching matrix

b $3 \times 3$ switching matrix
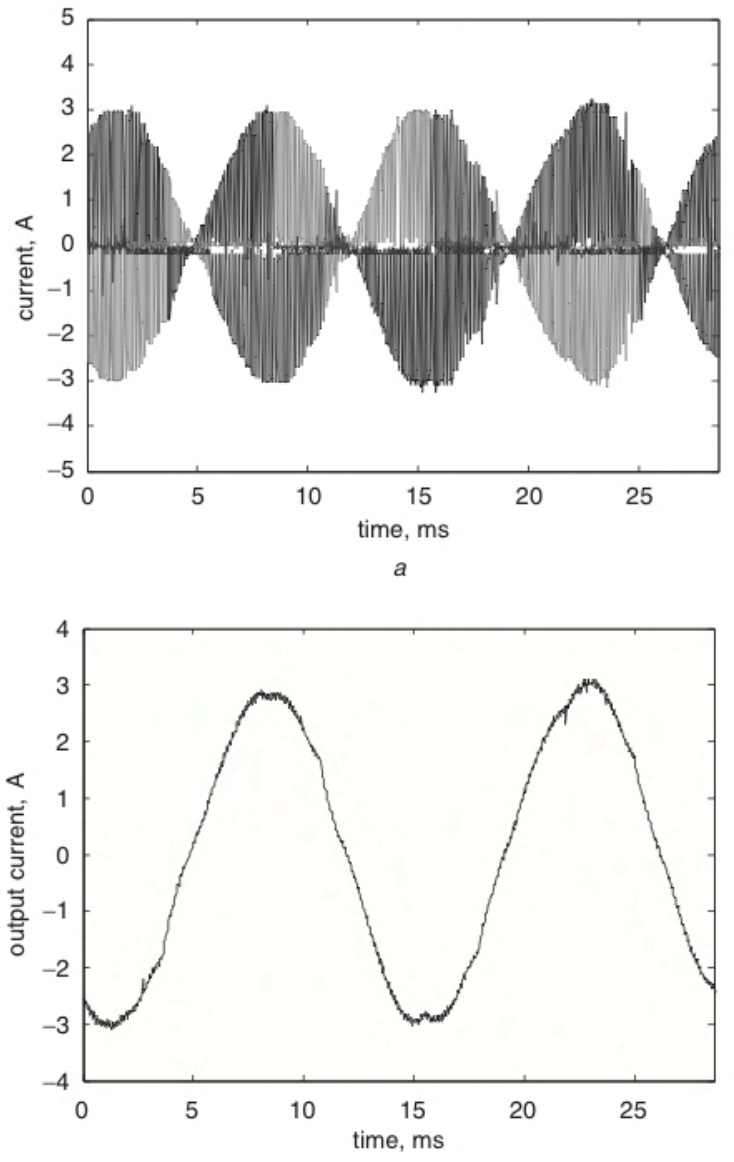

b

Fig. 9 Results taken at 400 bar from the $3 \times 2$ matrix converter $a$ input phase currents

$b$ output current

requiring a six-switch voltage/current source inverter fed from a rectifier, or, for this application field, the adoption of $3 \times 3$ matrix converters (Fig. $8 b$ ) to transform a $3 \phi$ fixed voltage/fixed-frequency input to a $3 \phi$ variable-voltage/ variable-frequency output, as a function of motor rotor position.

The use of matrix converters for control of PMSMs [21], in this case, is complicated by the fundamental requirement for high reliability in these systems, and has meant that the 'external component' count and connections/routing requirements attributed to the rotor position sensors for correct commutation of PMSMs onboard ROVs, is leading to increased interest in sensorless rotor-position estimation schemes. Moreover, where applications call for custom
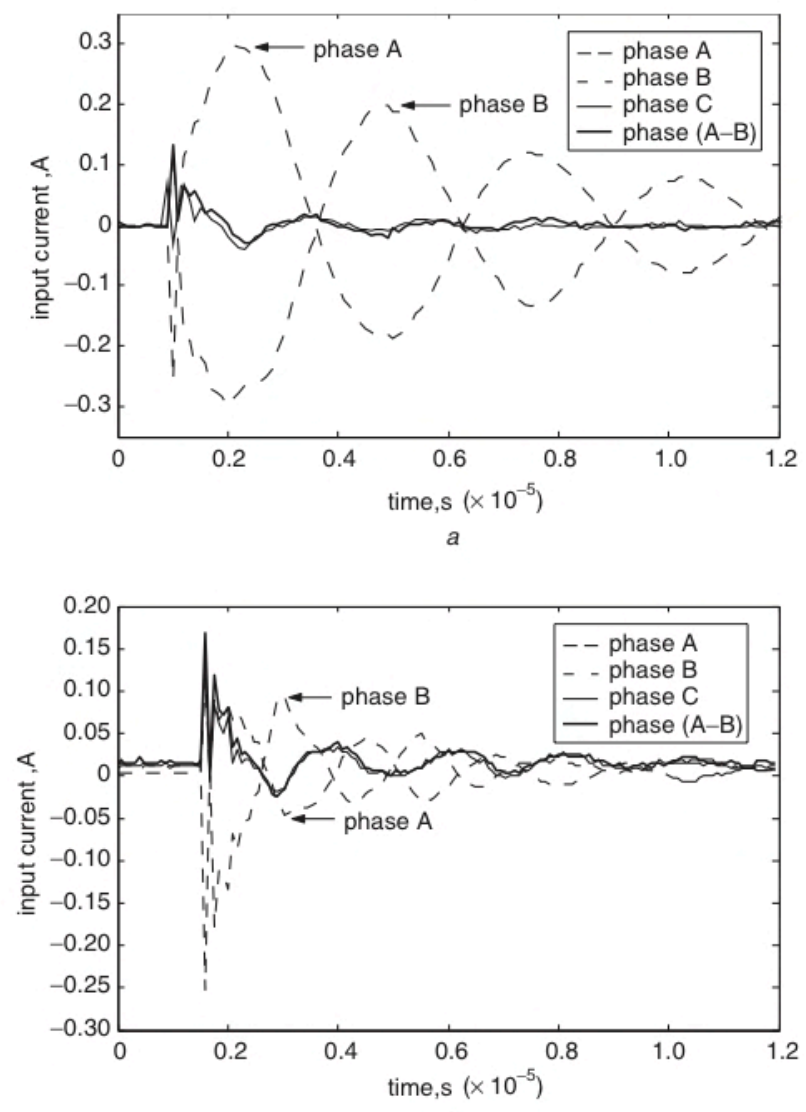

b

Fig. 10 Current transient on the 3rd comm. event $a$ with capacitive load $b$ without capacitive load

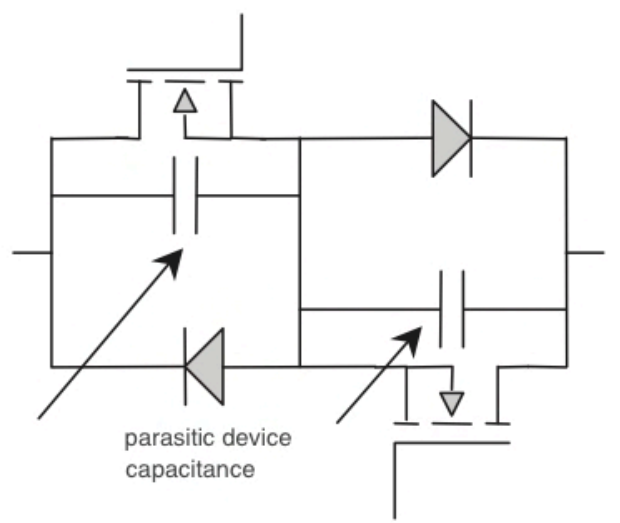

Fig. 11 Bidirectional switch configuration illustrating parasitic capacitance 

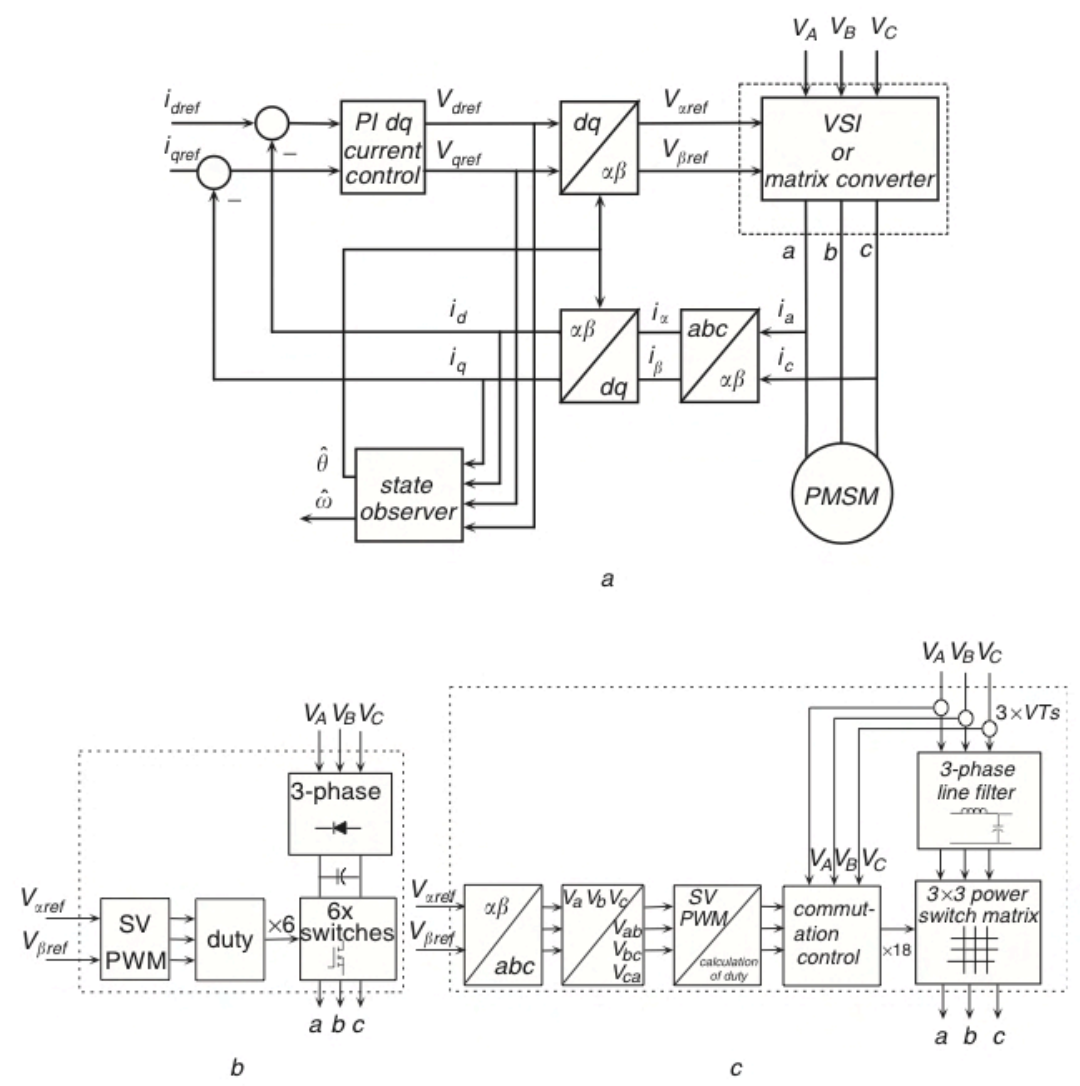

Fig. 12 Vector control schemes for sensorless control

$a$ structure of controller

$b$ implementation for voltage source inverter

$c$ implementation for matrix converter

motor designs, the omission of the rotor position sensor provides the additional benefit of allowing an increase in the active length of the rotor/stator, thereby increasing the power/torque obtained for a given volume envelope.

For servotype applications, and those where electromagnetic torque ripple can have a significant impact on overall product performance, vector control schemes (Fig. 12a) are preferred, and sensorless operation must be achieved using only motor terminal quantities to accurately estimate the rotor position. Although control of PMSMs using matrix converters has been previously reported [21], only recently has sensorless operation of PMSMs with matrix converters attracted attention $[11,12]$. In $[11,12]$ rotor position estimation techniques have been employed using voltage tuning in conjunction with stator flux estimation. However, here it is shown that by suitable choice of matrix converter commutation strategy, observer-based sensorless control methodologies previously developed for sensorless control of PMSMs using six-switch VSIs (Fig. 12b) [5, 7, 22-24], can be conveniently employed in applications where PMSMs are excited by matrix converters. In this way, the additional benefits attributed to observer-based techniques e.g. convenient load-torque estimation [7,22,23] for enhanced speed control, operation from zero speed and speed reversal $[22,23]$ are inherently accommodated.

\section{Observer-based sensorless control of PMSMs using matrix converters}

Two fundamental methodologies for correct control of the power switches of the matrix converter have been reported: the direct transfer method (DTM), given in [25], and the indirect transfer method (ITM) [26], based on the intermediate derivation of a pseudo DC-link. Here, the advantages of lower computational overhead [15,27] and the increased voltage transfer ratio attributed to ITM make it the preferred candidate. The desired switching sequence is the result of the product of a 'rectifier transfer function' (RTF) and the 'inverter transfer function' (ITF) [27]. The function of the RTF is to select two of the three input phase voltages (with respect to neutral) that will provide the highest potential, i.e. $\hat{V}_{i n}=V_{\max }-V_{\min }$, where

$$
\begin{aligned}
V_{\max } & =\max \left[V_{A}, V_{B}, V_{C}\right] \\
V_{\min } & =\min \left[V_{A}, V_{B}, V_{C}\right]
\end{aligned}
$$

Knowledge of the motor rotor position is then used by the matrix converter commutation algorithm to define two switching 'space vectors', $V_{x}, V_{y}$ that are adjacent to the desired output space vector $V_{o}$, to develop the required electromagnetic torque in the machine, as illustrated in Fig $13 a$. The duties $d_{x}, d_{y}$ for the power switching space vectors $V_{x}, V_{y}$, plus the zero-vector $\left(V_{z}\right)$ component, $d_{z}$, subsequently define how the matrix converter must be controlled at any instance in time, as a function of rotor position (Fig. 13b). The geometric calculations and the resulting power switch commutation sequences have been well documented, and the reader is referred to [27] for a full account. The maximum voltage that the output vector can achieve using this algorithm is given by

$$
V_{d c}=\frac{\sqrt{3}}{2} V_{i n}
$$

where $V_{\text {in }}$ is the RMS line input voltage.

A convenient relationship between observer-based sensorless control of PMSMs using VSIs and matrix 


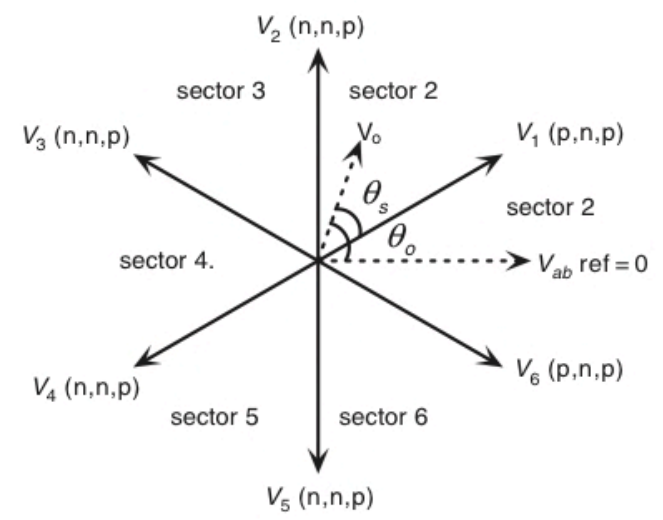

a

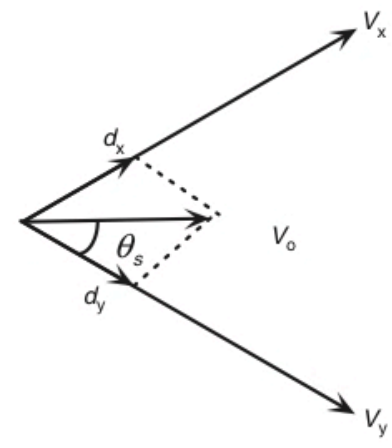

Fig. 13 Matrix converter

$a$ output voltage switching state vectors

$b$ space state sector

converters, is that motor line voltage demands can be directly employed to obtain the duty cycles for control of the matrix converter from knowledge of the rotor position and the magnitude of the 'artificial' DC-link voltage (2), and solved for the duty components (3), which in turn give the switching periods (4).

$$
\begin{gathered}
{\left[\begin{array}{c}
d_{x}+d_{y} \\
-d_{x} \\
-d_{y}
\end{array}\right]=\left[\begin{array}{l}
\bar{V}_{a b} \\
\bar{V}_{b c} \\
\bar{V}_{c a}
\end{array}\right] \cdot \frac{1}{V_{d c}}} \\
d_{x}=\frac{T_{x}}{T_{s}} \\
d_{y}=\frac{T_{y}}{T_{s}} \\
d_{z}=1-d_{x}-d_{y}
\end{gathered}
$$

The overall structure of a matrix converter-based PMSM control scheme is shown in Fig. 12c. By comparison with Fig. 12b, the common requirement for control of PMSMs using six-switch VSIs, and those of a matrix converter, can be seen. In particular, they both require knowledge of rotor position and demanded $V_{\alpha}$ and $V_{\beta}$, and feedback of motor phase currents. The calculation of switching duties for the matrix converter are then obtained from the value of the pseudo-DC-link voltage and the values of demanded $V_{\alpha}$ and $V_{\beta}$ transformed into equivalent demanded line voltages, $\bar{V}_{a b}, \bar{V}_{b c}, \bar{V}_{c a}$ (3). It is noted that the pseudo-DC-link voltage employed in the transformation to obtain demanded line voltages does not account for the $6 \times$ fundamental-frequency ripple presented by the input supply, which would develop electromagnetic torque ripple from the machine. However, these effects are abated if the current controller bandwidth is sufficiently high (typically $>1 \mathrm{kHz}$ for a $60 \mathrm{~Hz}, 3-\phi$ supply).

\subsection{PMSM rotor position estimation}

Observer-based rotor position estimation schemes are generally based on a dynamic model of the motor; the most convenient in this case being in $d-q$ rotor-fixed reference co-ordinates (5)

$$
\begin{aligned}
\frac{d}{d t} i_{d} & =-\frac{R_{s}}{L_{s}} i_{d}+\omega i_{q}+\frac{v_{d}}{L_{s}} \\
\frac{d}{d t} i_{q} & =-\frac{R_{s}}{L_{s}} i_{q}-\omega i_{d}-\frac{K_{e}}{L_{s}} \omega+\frac{v_{q}}{L_{s}} \\
\frac{d}{d t} \omega & =\frac{K_{t} p}{J} i_{q}-\frac{B}{J} \omega \\
\frac{d}{d t} \theta & =\omega
\end{aligned}
$$

where $R_{s}, L_{s}, K_{e}$ and $K_{t}$ are, respectively, the phase resistance, synchronous inductance, back-emf and torque constants; $J$ is the rotor inertia, $B$ is the motor viscous friction, $\omega$ is the rotor angular velocity, $\theta$ is the rotor position and $p$ denotes the number of pole pairs. Since only terminal quantities of the motor can be measured, the inputs are defined as $u=\left[v_{d}, v_{q}\right]^{T}$ and the measured outputs are $y=\left[i_{d}, i_{q}\right]^{T}$.

Design of the observer can be simplified by initially applying a feedback linearising controller (6) to the motor that renders the resulting dynamics essentially linear from an input/output perspective. This then allows classical linear observer-based design techniques to be subsequently employed for the estimation of state variables [7, 22, 23].

$$
\begin{aligned}
& u_{d}=v_{d}+\omega L_{s} i_{q} \\
& u_{q}=v_{q}-\omega L_{s} i_{d}
\end{aligned}
$$

A feature of employing feedback linearisation on the motor model in the rotor fixed $d-q$ co-ordinate system, (5), however, is that the rotor position, $\theta$, becomes unobservable at the outputs, and therefore cannot be subsequently estimated by a state observer. Although it is intuitive to integrate the estimated angular velocity $\hat{\omega}$, which is observable, to obtain $\hat{\theta}$, this does not account for offset, drift and divergence due to unknown initial conditions, measurement noise and modelling errors. Nevertheless, a classical Luenberger observer [7] is sufficient to estimate all states of a reduced-order model that neglects the 4th state $d \theta / d t=\omega$, in $(5)$.

$$
\begin{aligned}
\frac{d}{d t}\left[\begin{array}{l}
\hat{i}_{d} \\
\hat{i}_{q} \\
\hat{\omega}
\end{array}\right]= & {\left[\begin{array}{ccc}
-\frac{R_{s}}{L_{s}} & 0 & 0 \\
0 & -\frac{R_{s}}{L_{s}} & -\frac{\mathbf{K}_{e}}{L_{s}} \\
0 & \frac{K_{p} p}{J} & -\frac{B}{J}
\end{array}\right]\left[\begin{array}{c}
\hat{i}_{d} \\
\hat{i}_{q} \\
\hat{\omega}
\end{array}\right]+\left[\begin{array}{cc}
\frac{1}{L_{s}} & 0 \\
0 & \frac{1}{L_{s}} \\
0 & 0
\end{array}\right]\left[\begin{array}{l}
u_{d} \\
u_{q}
\end{array}\right] } \\
& +K\left[\begin{array}{c}
i_{d}-\hat{i}_{d} \\
i_{q}-\hat{i}_{q}
\end{array}\right]
\end{aligned}
$$

Subsequently, a solution to the problem of estimating $\hat{\theta}$, described in [28], is employed, where a corrective mechanism based on measured (or demanded) $v_{d}$, and an estimated value, $v_{d}^{\prime}$, determined from the measured currents (8).

$$
\left[\begin{array}{c}
v_{d}^{\prime} \\
v_{q}^{\prime}
\end{array}\right]=\left[\begin{array}{cc}
R_{s}+\frac{d}{d t} L_{s} & -L_{s} \omega \\
L_{s} \omega & R_{s}+\frac{d}{d t} L_{s}
\end{array}\right]\left[\begin{array}{l}
i_{d} \\
i_{q}
\end{array}\right]+K_{e} \omega\left[\begin{array}{l}
0 \\
1
\end{array}\right]
$$

An estimate-correction action to facilitate convergence of $\hat{\theta}$ towards $\theta$, is then obtained from the $d$-axis voltage error $\left(v_{d}-v_{d}^{\prime}\right)$, which is approximately proportional to the error in rotor angle. The complete rotor position estimation scheme therefore consists of, (i) a feedback linearising controller (6), 


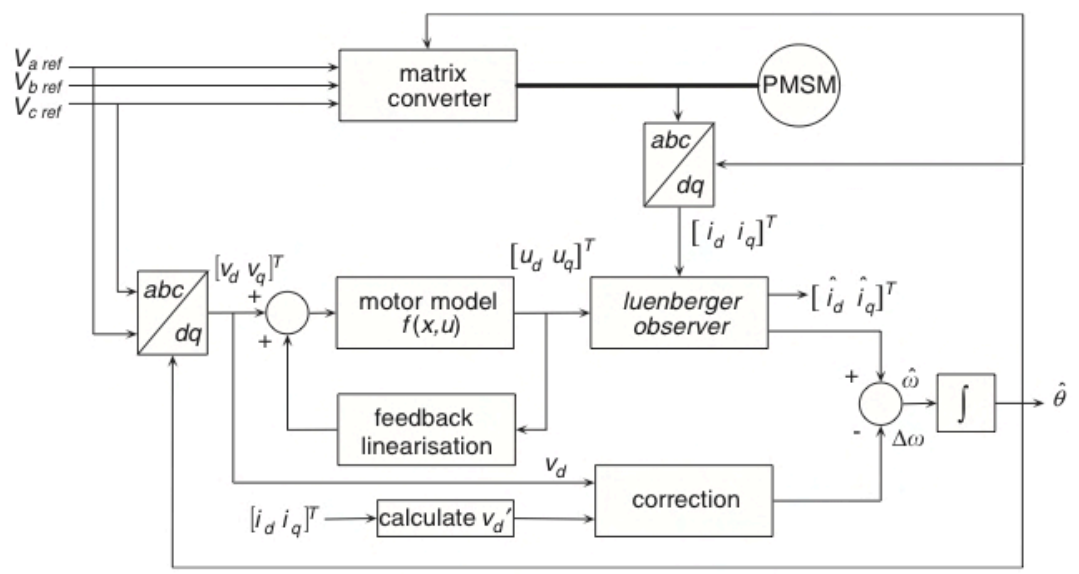

Fig. 14 Feedback linearisation followed by application of a linear state-estimator and employing correction scheme

(ii) a linear observer (7), and (iii) a correction scheme to allow $\hat{\theta}$ to converge to $\theta$ (see Fig. 14).

Design of the observer gain matrix, $\mathbf{K}$ (7), is motor dependent, but consists of assigning the eigenvalues of the observer to be sufficiently fast compared to the motor electrical dynamics so that the transient convergence of the state estimates has minimum impact on the outer-loop control system. In this case, the observer gain matrix is given in (9), which assigns the eigenvalues of the observer at $\lambda=\{-2600,-1600,-800\}$

$$
\mathbf{K}=\left[\begin{array}{cc}
99 & -256 \\
12 & 2000 \\
61 & -113668
\end{array}\right]
$$

\subsection{Experimental results}

The presented matrix converter sensorless scheme has been employed to provide sensorless control of a $0.7 \mathrm{~kW}, 6$-pole PMSM with a base speed of $3000 \mathrm{rpm}$. The algorithms are implemented on a TI TMS320C31 DSP hardware development platform. Figures $15 a$ and $b$ show, respectively, measured and estimated angular velocity when operating at $\approx 2000 \mathrm{rpm}$, and the measured and estimated rotor position and position error. It can be seen that the position error under steady-state conditions is $<0.1 \mathrm{rad}$.

An additional and convenient feature of adopting observer-based rotor position estimation schemes is the ability to readily expand the number of observed states to include estimates of load torque or motor parameters (e.g. stator resistance) [29-31]. By way of example, load torque can be observed by augmenting the state equations with $d T_{L} / d t=0$ (10), where $T_{L}$ represents the estimated load torque disturbance, and is advantageous for both enhancing the accuracy of the rotor position estimates when the motor is subject to transient and heavy loading, and to facilitate the commonly used technique of feedforward to enhance disturbance rejection performance.

$$
\begin{aligned}
\frac{d}{d t} \omega & =\frac{K_{t} p}{J} i_{q}-\frac{B}{J} \omega-\frac{T_{L} p}{J} \\
\frac{d}{d t} T_{L} & =0
\end{aligned}
$$

The advantage of including load torque in the observer can be seen by referring to Figs. 16 and 17, which show the motors response to a step load of $0.2 \mathrm{Nm}$ at $t=0$, without the load torque state included in the observer, and with the state included, respectively. In particular, Fig. $16 b$ shows a
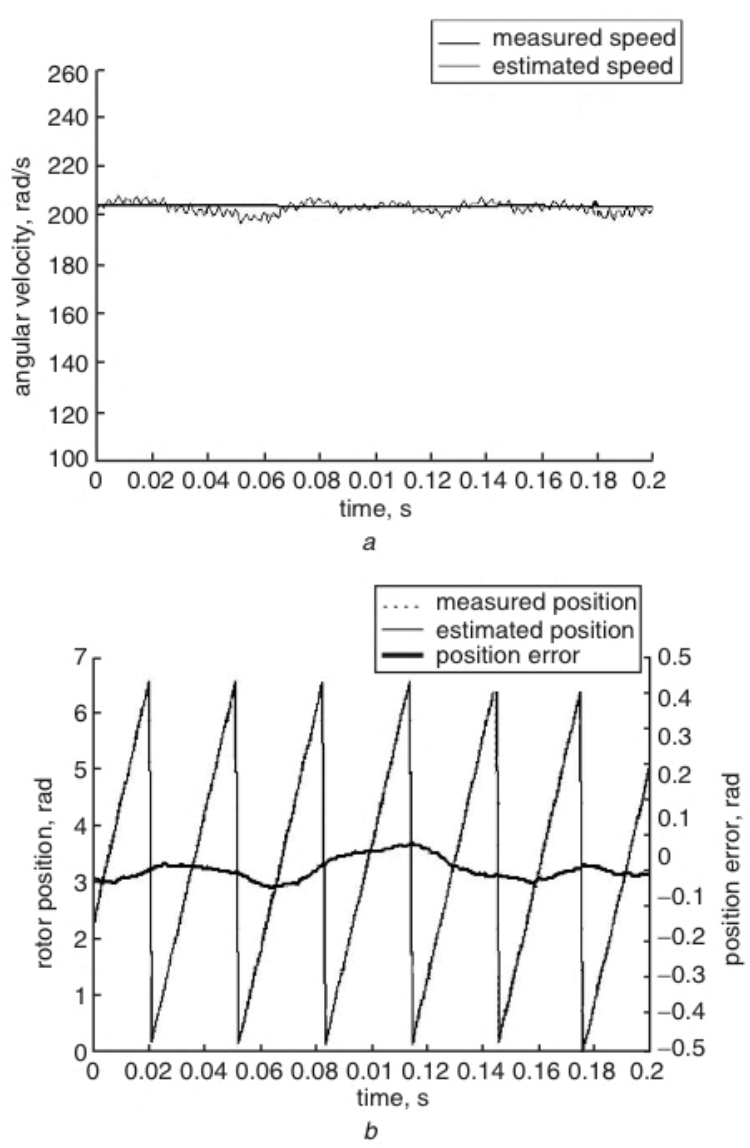

Fig. 15 Steady-state operation

$a$ measured and estimated angular velocity

$b$ measured and estimated rotor position and rotor position error

steady-state position error of $0.25 \mathrm{rad}$ after the load is applied, while, by comparison, a significant improvement in rotor position accuracy, by inclusion of load torque state, is shown in Fig. 17. It is notable that the low power operation ( $\approx 6 \%$ full-load torque) depicted by these results constitutes one of the most arduous operating conditions for observerbased sensorless techniques since performance is dominated by the current convergence dynamics, and are reliant on phase current measurements that are of low amplitude and particularly noise-prone by virtue of the applied low-duty phase voltages. Degradation of rotor position estimates under such conditions can ultimately have impact on acceleration dynamics and startup behaviour [22, 23]. 

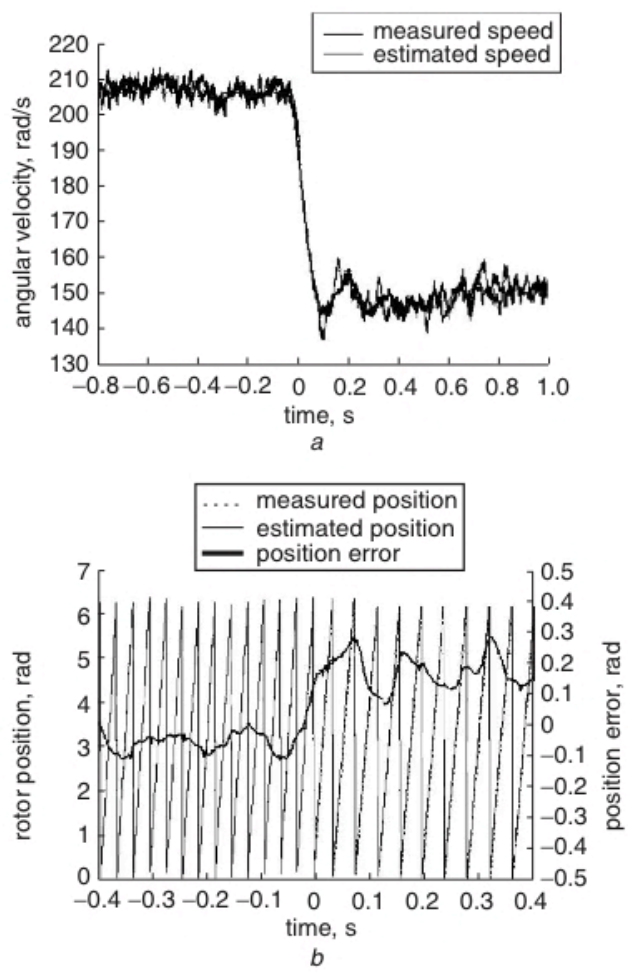

Fig. 16 Luenberger observer under transient operation $0.2 \mathrm{Nm}$ applied at $\approx 0 \mathrm{~s}$

$a$ measured and estimated angular velocity

$b$ measured and estimated rotor position and position error

\section{Conclusion \& discussion}

The use of matrix converter technologies has been investigated to address key requirements for power converters onboard all-electric, work-class, deep-sea ROVs, where systems are expected to sustain operation at high ambient pressures, up to $300 \mathrm{bar}$, commensurate with operation of ROVs at $3000 \mathrm{~m}$.

For the majority of industrial applications, the conventional VSI would facilitate the most economical PM synchronous machine drive. However, smoothing of the DC-link requires large electrolytic capacitors that have been shown to withstand operation in subsea environments only when enclosed in large (high mass) air-filled chambers at atmospheric pressure. Matrix converters, on the other hand, eliminate the requirement for such components, although they do require three additional measurements of input phase voltages over and above those required for VSI counterparts, along with associated signal processing and interface circuitry. Nevertheless, the additional volume envelope required for these low-power electronic components remains much less than typical DC-link capacitors used in VSIs.

Both $3 \times 2$ matrix converters, for $3 \phi-1 \phi$ AC voltage/ frequency conversion control of system auxiliaries, and $3 \times 3$ matrix converters for control of actuators driven by brushless PMSMs, are considered, manufactured from electronic components that have been demonstrated to maintain operation at high pressure. Particular emphasis is given to sensorless operation of PMSMs with $3 \times 3$ matrix converters with a view to minimising external cabling/ routing requirements, and simplifying motor designs by virtue of not having to house and seal rotor position sensors and associated electronics in the motor casing. It is shown that observer-based sensorless schemes, developed for control of PMSMs with traditional VSIs, can be readily applied to variants driven matrix converters, with experi-
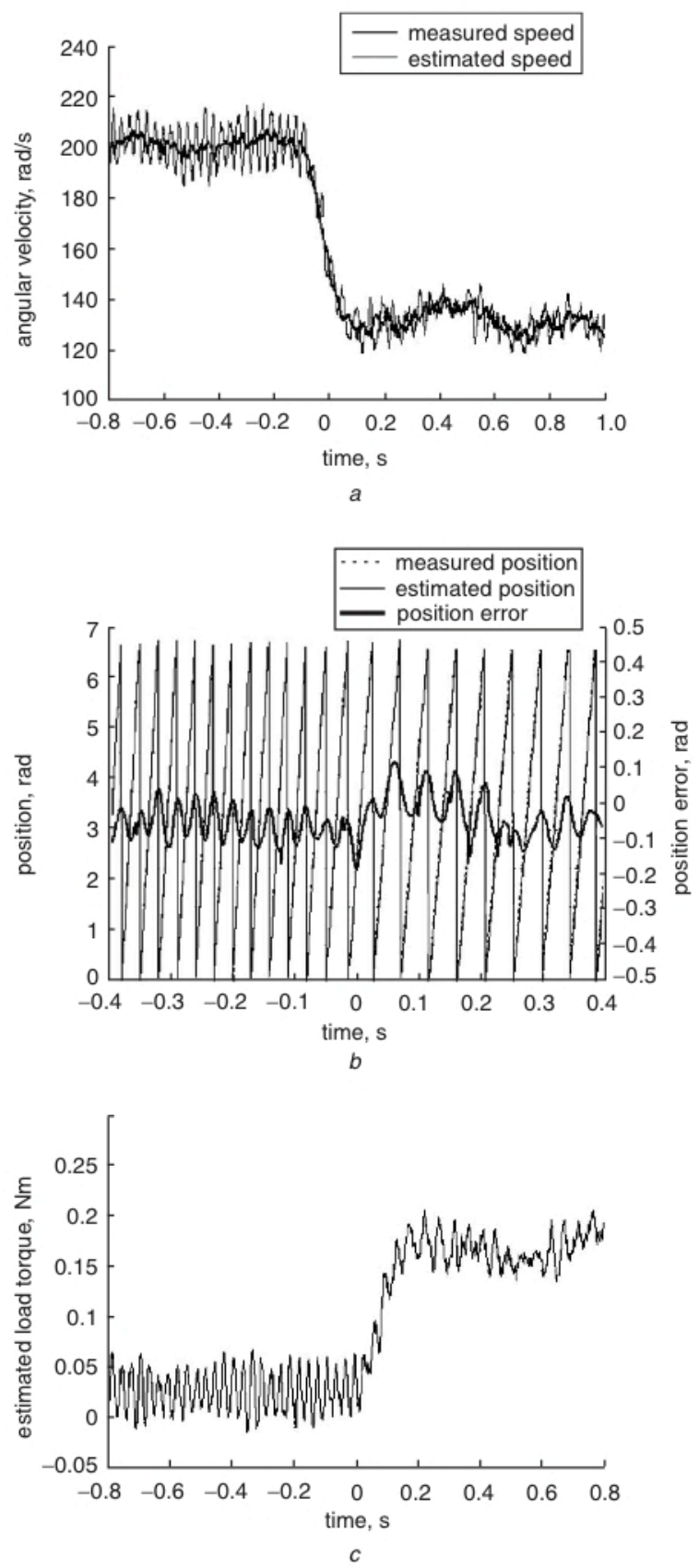

Fig. 17 Luenberger observer including load torque estimation $0.2 \mathrm{Nm}$ applied at $\approx 0 \mathrm{~s}$

$a$ measured and estimated angular velocity

$b$ measured and estimated rotor position and position error $c$ estimated load torque

mental results showing the benefits of employing such schemes.

While the omission of a rotor position sensor provides significant advantages, research is continuing to provide further reductions in sensor components by utilising the demanded reference voltages rather than measured motor terminal voltages, and, ultimately, transforming the measured motor phase currents to obtain the input currents to the matrix converter to reduce the number of current sensors employed.

\section{References}

1 Abu-Sharkh, M.S., Harris, M.R., and Crowder, R.M.: 'Comparative studies of electric and hydraulic drive system for thrusters of remotely operated vehicles'. Presented at Oceanology Int. Conf., Brighton, UK, 1994 
2 Abu-Sharkh, M.S., Harris, M.R., and Stoll, R.L.: 'Design and performance of an integrated thruster motor'. 7th Int. Conf. on Electrical Machines and Drives, Durham, UK, 1995, pp. 395-399

3 Snary, P., Bingham, C.M., Stone, D.A., and Schofield, N.: 'Drive system for operation on deep sea ROVs'. EPE 2003, Toulouse, France, 2003

4 Schilling, T.: 'The remote systems engine: ROV subsystems that work together', ON\&T, , January/February 1999

5 Bado, A., Bologani, S., and Zigliotto, M.: 'Effective estimation of speed and rotor position of an PM synchronous motor drive by a Kalman filtering technique', IEEE Proc. PESC, 1992, pp. 951-957

6 Zhu, G., Kaddouri, A., Dessiant, L. and Akhrif, O.: 'A nonlinear state observer for the sensorless control of a permanent-magnet $\mathrm{AC}$ machine', IEEE Trans. Ind. Electron., 2001, 48, pp. 1098-1108

7 Hamada, D., Uchida, K., Yusivar, L.F., Wakeo, S., and Onuki, T.: Sensorless control of PMSM using a linear reduced order observer including disturbance torque estimation'. Presented at EPE' 99. Lausanne, Switzerland, 1999

8 Solsona, J., and Muravchik, C.: 'A nonlinear reduced order observer for permanent magnet synchronous rotors', IEEE Trans. Ind. Electron., 1996, 43, pp. 492-497

9 Bolognani, S., Oboe, R., and Zigliotto, M.: 'Sensorless full-digital PMSM drive with EKF estimation of speed and rotor position', IEEE Trans. Ind. Electron., 1999, 46, pp. 184-191

10 Salvatore, L., and Stasi, S.: 'Application of EKF to parameter and state estimation of PMSM drive', IEEE Proc., 1992, 139, pp. $155-164$

11 Tain-Hua-Liu, ., Szu-Han-Chen, ., and Der-Fa-Chen, .: 'Design and implementation of a matrix converter PMSM drive without a shaft sensor', IEEE Trans. Aerosp. Electr. Syst., 2003, 39, pp. 228-243

12 Chen, D.-E., Liu, T.-H, and Chen, S.-H.: 'Implementation of a novel sensorless matrix converter PMSM drive'. Proc. 4th IEEE Int. Conf. on Power electronics and drive systems., Indonesia, 2001, Vol. 2, pp. $718-724$

13 Large, L.S., Green, A., Mason, S.C., Bhatia, S., Clare, J.C., Zanchetta, P., Empringham, L, and Wheeler, P.W. 'Matrix converter solution for aircraft starting'. IEE Seminar matrix converters, London, UK, 2003, pp. 5/1-18

14 Whitley, C.R., Towers, G.K., Wheeler, P., Clare, J., Bradley, K., Apap, M., and Empringham, L.A.: 'Matrix converter based electrohydrostatic actuator'. IEE Seminar matrix converters, London, UK, pp. $6 / 1-5$

15 Wheeler, P.W., Rodriguez, J., Clare, J.C., Empringham, L., and Weinstein, A.: 'Matrix converters: a technology review', IEEE Trans. Ind. Electron., 2002, 49, (2), pp. 276-288

16 Empringham, L., Wheeler, P.W., and Clare, J.C.: 'Matrix converter bi-directional switch commutation using intelligent gate drives'. 7th Int. Conf. on Power electronics and variable speed drive, London, UK, 1998, pp. 626-63
17 Kwon, B.H., Min, B.D., and Kim, J.H.: 'Novel commutation technique of AC-AC converters', IEE Proc. Electr. Appl., 1998, 145, (4), pp. 295-300

18 Nielsen, P., Blaabjerg, F., and Pedersen, J.K.: 'New protection issues of a matrix converter: design for adjustable-speed drives', IEEE Trans. Ind. Appl., 1999, 35, (5), pp. 1150-1161

19 Youm, J.H., and Kwon, B.H.: 'Switching technique for current controlled AC-to-AC converters', IEEE Tran. Ind. Electron., 1999, 46, (2), pp. 309-318

20 Neft, C.L., and Schauder, C.D.: 'Theory and design of 30-hp matrix converter', IEEE Trans. Ind. Appl, 1992, 28, (3) pp. 546-551.

21 Bouchiker, S., Capolino, G.A., and Poloujadoff, M. 'Vector control of a permanent-magnet synchronous motor using AC-AC matrix converter', IEEE Trans. Power Electron., 1998, 13, (6)

22 Bhangu, B., and Bingham, C.M.: 'Nonlinear state-observer techniques for sensorless control of automotive PMSMs, including load-torque estimation and saliency'. EPE 2003, Toulouse, France, 2003

23 Bhangu, B., Williams, C., Bingham, C.M., and Coles, J.: 'EKFs and other nonlinear state-estimation techniques for sensorless control of automotive PMSMs'. Proc. SPEEDAM, Ravello, Italy, 2002, pp. C5 33-38

24 Dhaouadi, R., Mohan, N., and Norum, L.: 'Design and implementation of an extended Kalman filter for the state estimation of a permanent magnet synchronous motor', IEEE Trans. Power Electron., 1999, 6, pp. 491-497

25 Alesina, A., and Venturini, M.G.B.: 'Solid-state power conversion: a Fourier analysis approach to generalised transformer synthsis', IEEE Trans. Circuit Syst., 1981, 28, (4), pp. 319-330

26 Rodriguez, J.: 'A new control technique for AC-AC converters'. Proc. IFAC Control in power electronic and electrical drives Conf., Lauanne, Switzerland, 1983, pp. 203-2087

27 Huber, L., and Borojevic, D.: 'Space vector modulated three-phase to three-phase matrix converter with input power factor correction', IEEE Trans. Ind. Appl., 1995, 31, (6), pp. 1234-1246

28 Matsui, N., and Shigyo, M.: 'Brushless dc motor control without position and speed sensors', IEEE Trans. Ind. Electron., 1992, 28, pp. $120-127$

29 Acarnley, P.P., and Al-Tayie, J.K.: 'Estimation of speed and armature temperature in a brushed DC drive using the extended Kalman filter'. IEE Proc. Electr. Power Appl., 1997, 144, (1), pp. 13-20

30 Cambell, J., Sumner, M., and Curtis, M. 'An improved sensorless vector controlled induction motor drive employing artificial neural networks for stator resistance estimation'. Proc. Eigth Int. Conf. on power electronics and variable speed drives, London, UK, 2000, pp. 247-249

31 Acarnley, P.P., and Al-Tayie, J.K.: 'Combined speed and temperature estimation in brushed DC drives'. Proc. Eur. Conf. on power electronics and applications, Brussels, Belgium, 1995, Vol. 1, 144, pp. $735-740$ 